\title{
GPR179 Is Required for High Sensitivity of the mGluR6 Signaling Cascade in Depolarizing Bipolar Cells
}

\author{
Thomas A. Ray, ${ }^{1 \star}$ Kathryn M. Heath, ${ }^{2 \star}$ Nazarul Hasan, ${ }^{1}$ Jennifer M. Noel, ${ }^{3}$ Ivy S. Samuels, ${ }^{4}$ Kirill A. Martemyanov, ${ }^{5}$ \\ Neal S. Peachey, ${ }^{4,6,7}$ Maureen A. McCall, ${ }^{2,8}$ and Ronald G. Gregg ${ }^{1,8}$ \\ ${ }^{1}$ Department of Biochemistry and Molecular Biology, University of Louisville, Louisville, Kentucky 40202, ${ }^{2}$ Department of Psychological and Brain Sciences, \\ University of Louisville, Louisville, Kentucky 40292, ${ }^{3}$ Department of Anatomical Sciences and Neurobiology, University of Louisville, Louisville, Kentucky \\ 40202, ${ }^{4}$ Louis Stokes Cleveland VA Medical Center, Cleveland, Ohio 44106, ${ }^{5}$ Department of Neuroscience, The Scripps Research Institute, Jupiter, Florida \\ 33458, ${ }^{6}$ Cole Eye Institute, Cleveland Clinic, Cleveland, Ohio 44195, ${ }^{7}$ Department of Ophthalmology, Cleveland Clinic Lerner College of Medicine of Case \\ Western Reserve University, Cleveland, Ohio 44195, and ${ }^{8}$ Department of Ophthalmology and Visual Sciences, University of Louisville, Louisville, Kentucky \\ 40202
}

Parallel visual pathways are initiated at the first retinal synapse by signaling between the rod and cone photoreceptors and two general classes of bipolar cells. For normal function, $\mathrm{ON}$ or depolarizing bipolar cells (DBCs) require the G-protein-coupled receptor, mGluR6, an intact G-protein-coupled cascade and the transient receptor potential melastatin 1 (TRPM1) cation channel. In addition, another seven transmembrane protein, GPR179, is required for DBC function and recruits the regulators of G-protein signaling (RGS) proteins, RGS7 and RGS11, to the dendritic tips of the DBCs. Here we use the Gpr179 ${ }^{\text {nob }}$ mouse, which lacks GPR179 and has a no b-wave electroretinogram (ERG) phenotype, to demonstrate that despite the absence of both GPR179 and RGS7/RGS11, a small dark-adapted ERG b-wave remains and can be enhanced with long duration flashes. Consistent with the ERG, the mGluR6-mediated gating of TRPM1 can be evoked pharmacologically in $G \operatorname{pr} 179^{n o b 5}$ and $R G S 7^{-/-} / R G S 11^{-/-}$rod BCs if strong stimulation conditions are used. In contrast, direct gating of TRPM1 by capsaicin in $R G S 7^{-/-} / R G S 11^{-/-}$and WT rod BCs is similar, but severely compromised in Gpr179 $9^{\text {nob5 }}$ rod BCs. Noise and standing current analyses indicate that the remaining channels in Gpr $179^{\text {nob5 }}$ and $R G S 7^{-/-} / R_{G S 11^{-/-}}$rod BCs have a very low open probability. We propose that GPR179 along with RGS7 and RGS11 controls the ability of the mGluR6 cascade to gate TRPM1. In addition to its role in localizing RGS7 and RGS11 to the dendritic tips, GPR179 via a direct interaction with the TRPM1 channel alters its ability to be gated directly by capsaicin.

Key words: GPR179; mGluR6; night blindness; retina; rod bipolar; TRPM1

\section{Introduction}

Visual processing in the mammalian retina is initiated through parallel vertical pathways that are established at the synapse between photoreceptors and bipolar cells (BCs). In the dark, photoreceptors constantly release glutamate and in response to a light increment they hyperpolarize, decreasing glutamate release. Two general classes of BCs form synapses with cone photoreceptor terminals and are defined by their response to a light increment.

Received Sept. 20, 2013; revised March 13, 2014; accepted March 26, 2014.

Author contributions: T.A.R., K.M.H., N.S.P., M.A.M., and R.G.G. designed research; T.A.R., K.M.H., N.H., J.M.N., I.S.S., and N.S.P. performed research; K.A.M. contributed unpublished reagents/analytic tools; T.A.R., K.M.H., N.H., J.M.N., N.S.P., and M.A.M. analyzed data; T.A.R., K.M.H., N.S.P., M.A.M., and R.G.G. wrote the paper.

This work was supported by funding from the National Institutes of Health (R01 EY12354, R.G.G.; R01 014701, M.A.M.; R21 EY21852, N.S.P. and R.G.G.; R01 EY018139, K.A.M.), the Foundation Fighting Blindness, the Department of Veterans Affairs, and unrestricted grants from Research to Prevent Blindness to the University of Louisville and the Cleveland Clinic Lerner College of Medicine of Case Western Reserve University.

*T.A.R. and K.M.H. contributed equally to this work.

The authors declare no competing financial interests.

Correspondence should be addressed to either Ronald G. Gregg or Maureen A. McCall, Department of Biochemistry and Molecular Biology, University of Louisville, 319 Abraham Flexner Way, Louisville, KY 40202, E-mail: ron.gregg@louisville.edu or mo.mccall@louisville.edu.

DOI:10.1523/JNEUROSCI.4044-13.2014

Copyright $\odot 2014$ the authors $\quad 0270-6474 / 14 / 346334-10 \$ 15.00 / 0$
Hyperpolarizing BCs signal via ionotropic glutamate receptors of the AMPA/kainate type (Kaneko and Saito, 1983; Saito and Kaneko, 1983; Slaughter and Miller, 1983) and depolarizing BCs (DBCs) signal via the metabotropic glutamate receptor 6 (mGluR6; Masu et al., 1995). A single class of rod BC is postsynaptic to rod photoreceptors (Boycott et al., 1969). As a result, defects at this synapse lead to complete congenital stationary night blindness (cCSNB). This defect is detected by the absence of the b-wave in the electroretinogram (ERG) in both humans and animal models (Miyake et al., 1986; McCall and Gregg, 2008).

The rod BC light-evoked response is initiated by a decrease in glutamate occupancy of mGluR6, which decreases its G-protein activity culminating in the opening of the TRPM1 channel (Audo et al., 2009; Li et al., 2009; Morgans et al., 2009, 2010; Shen et al., 2009; Koike et al., 2010; Peachey et al., 2012a). The mGluR6-mediated modulation of TRPM1 also is known to require several other proteins including $\mathrm{G} \alpha$ o and G $\beta 3$ (Dhingra et al., 2000, 2002, 2012; Koike et al., 2010), and the regulators of G-proteins G $\beta 5$, RGS7, and RGS11 (Morgans et al., 2007; Jeffrey et al., 2010; Cao et al., 2012). Other known components with unresolved function include the following: 
nyctalopin, GPR179, and LRIT3 (Gregg et al., 2003; Audo et al., 2012; Peachey et al., 2012b; Zeitz et al., 2013).

GPR179 is a seven transmembrane protein that is absent in the Gpr179 ${ }^{\text {nob5 }}$ mouse mutant because of a transposable element insertion into the Gpr179 gene, which presents as a recessively inherited no b-wave phenotype in the ERG (Peachey et al., 2012b). GPR179 interacts with and is required for RGS7 and RGS11 localization to the DBC dendritic tips (Orlandi et al., 2012). To gain further insight into the role of GPR179 in the rod BC light response, we studied and compared Gpr179 ${ }^{n o b 5}, R_{G S 7^{-1-}}$, $R G S 11^{-/-}$, and WT mice.

We show that protein expression and outer plexiform layer (OPL) localization of both mGluR6 and TRPM1 are independent of GPR179 expression and that GPR179 and TRPM1 proteins interact. Functional analysis using ERG and whole-cell, patchclamp recording of rod BCs confirms that TRPM1-mediated currents are present in both $G$ pr $179^{\text {nob } 5}$ and $R G S 7^{-/-} / R_{G S 11^{-/-}}$rod $\mathrm{BCs}$, although the sensitivity of the mGluR6 cascade is significantly lower in each compared with WT. The Gpr179 nobs and $\mathrm{RGST}^{-/-} / \mathrm{RGS11}^{-/-}$mutants differ in the direct gating of TRPM1 by capsaicin, which is similar in WT and $R G S 7^{-1-}$ / $R G S 11^{-1-}$ rod BCs and severely compromised in Gpr $179^{\text {nob5 }} \mathrm{rod}$ BCs. Together, our results suggest that the sensitivity of the mGluR6 signaling cascade is set by the GPR179/RGS7/RGS11 complex, whereas an interaction between GPR179/TRPM1 sets the sensitivity of gating of the TRPM1 channel.

\section{Materials and Methods}

Animals. All procedures were performed in accordance with the Society for Neuroscience policies on the use of animals in research and each local Institutional Animal Care and Use Committees. Descriptions of all mice used have been published previously (Masu et al., 1995; Pardue et al., 1998; Pearring et al., 2011; Cao et al., 2012; Peachey et al., 2012b) and every line was either generated on a C57BL/6J background or backcrossed onto this background for at least six generations. All mice were housed in local Association for Assessment and Accreditation of Laboratory Animal Care approved facilities under a $12 \mathrm{~h}$ light/dark cycle. Animals of either sex were used in the experiments.

Antibodies. In experiments to examine the pattern of protein expression in the OPL, the following primary antibodies (and their concentrations) were used: sheep anti-GPR179 (1:2000; peptide KVQEETPGEDLDRPVLQKR; Peachey et al., 2012b), mouse monoclonal anti-ctbp2/Ribeye (1:1000; BD Bioscience), guinea pig anti-mGluR6 (1:1000; Koike et al., 2010), sheep anti-TRPM1 (1:1000; Cao et al., 2011), rabbit anti-GFP (1:800), and rhodamine peanut agglutinin (PNA) conjugate 566 (1:1000; Vector Laboratories). Secondary antibodies (Invitrogen; 1:1000) appropriate to each primary antibody included the following: donkey anti-sheep Alexa 488, donkey anti-rabbit Alexa 680, donkey anti-rabbit Alexa 546, donkey anti-mouse Alexa 647, and donkey anti-guinea pig Cy3 (1:1000; Millipore). In lieu of an antibody specific to nyctalopin, we used $\mathrm{Tg}(\mathrm{Gabrr1}-Y \mathrm{FP} / \text { nyx })^{R g g} 1$ transgenic mice, which express a yellow fluorescent protein (YFP)-tagged nyctalopin (Gregg et al., 2007). They are labeled WT in the figures.

Immunochemistry. Mice were anesthetized, their eyes were enucleated, and the lens was removed. Eyecups were washed in PBS then fixed for 30 min in $4 \%$ paraformaldehyde PBS solution, $\mathrm{pH}$ 7.4. Eyecups were washed three times in PBS then cryoprotected in increasing concentrations of sucrose in PBS $(10 \%, 15 \%$ for $1 \mathrm{~h}$ each and $20 \%$ overnight). Eyecups were embedded in 2:1 OCT/20\% sucrose PBS solution frozen in a liquid nitrogen-cooled bath of isopentane. Eyecups were sectioned (18 $\mu \mathrm{m}$ ) using a Leica 1850 cryostat, mounted on glass slides, and stored at $-70^{\circ} \mathrm{C}$. Sections were warmed to $37^{\circ} \mathrm{C}$ and washed with PBS and PBS containing $0.05 \%$ Triton X-100 (PBX) for 5 min each, then blocked in PBX 5\% normal donkey serum blocking solution for $1 \mathrm{~h}$. Sections were incubated overnight at room temperature in the presence of the primary antibody diluted in blocking solution, then washed three times for 10 min each with PBX followed by incubation in secondary antibody in PBX for $1 \mathrm{~h}$ at room temperature. Sections were washed for $10 \mathrm{~min}$ in PBX twice and in PBS once and coverslipped using Immu-Mount (Thermo Scientific). Slides were imaged using an Olympus FV1000 confocal microscope. Images were universally adjusted for brightness using Photoshop.

Mass spectrometry. After killing the mice, retinas were isolated from WT mice and homogenized in lysis buffer (1\% Nonidet P-40, $2 \mathrm{~mm}$ EDTA, and $20 \mathrm{~mm}$ HEPES, pH 7.4, supplemented with protease inhibitor cocktail) by rotating at $4^{\circ} \mathrm{C}$ for $45 \mathrm{~min}$. Samples were centrifuged at $17,000 \times g$ for $20 \mathrm{~min}$ to remove the debris, and supernatant was precleaned with Dynabeads (Invitrogen) for $1 \mathrm{~h}$ at $4^{\circ} \mathrm{C}$. Samples were incubated with TRPM1 or GPR179 antibody overnight at $4^{\circ} \mathrm{C}$. Lysates and antibody complexes were incubated with Dynabeads for $1.5 \mathrm{~h}$ at $4^{\circ} \mathrm{C}$. Protein complexes were eluted with NuPAGE LDS sample buffer (Invitrogen) and electrophoresed on NuPAGE gel (Invitrogen) until the highest molecular weight standard ( $260 \mathrm{kDa})$ had moved $\sim 5 \mathrm{~mm}$ into the gel. Electrophoresed gel pieces were cut from the top of the gel and an in-gel tryptic digestion was performed as described previously (Rood et al., 2010).

The resulting peptide mixture was resolved by liquid chromatography (LC) using an EASY n-LC (Thermo Scientific) UHPLC system with buffer A ( $2 \% \mathrm{v} / \mathrm{v}$ acetonitrile/ $0.1 \% \mathrm{v} / \mathrm{v}$ formic acid) and buffer B $(80 \% \mathrm{v} / \mathrm{v}$ acetonitrile $/ 0.1 \% \mathrm{v} / \mathrm{v}$ formic acid) as mobile phases. The mass spectrometry data from LC elutes was collected using an Orbitrap Elite ETD mass spectrometer (Thermo Scientific). A decision tree was used to determine whether CID or ETD activation was used. Proteome Discoverer v1.3.0.330 was used to analyze the data collected by the mass spectrometer. Scaffold v3.6.5 was used to calculate the false discovery rate using the peptide and protein prophet algorithms.

Cell culture, transfection, and immunoblotting. Human Embryonic Kidney (HEK293T) cells were cultured in high-glucose DMEM supplemented with $10 \%$ fetal bovine serum, $2 \mathrm{~mm}$ L-glutamine, $50 \mathrm{IU} / \mathrm{ml}$ penicillin, and $50 \mu \mathrm{g} / \mathrm{ml}$ streptomycin. One day before transfection, cells were seeded on $60 \mathrm{~mm}$ culture dishes. Gpr179 and Trpm1 expression plasmids were transfected into HEK293T cells using jetPrime reagent (Polyplus transfection) or Lipofectamine 2000 (Invitrogen) according to the manufacturer's instructions. After $24-48 \mathrm{~h}$ of transfection, cells were harvested in NP-40 lysis buffer ( $50 \mathrm{~mm}$ Tris, $150 \mathrm{~mm} \mathrm{NaCl}, 2$ mm EDTA, and $1 \%$ Nonidet $\mathrm{P} 40, \mathrm{pH} 8.0$, supplemented with protease inhibitor cocktail; Sigma-Aldrich) by rotating for $45 \mathrm{~min}$ at $4^{\circ} \mathrm{C}$ and centrifuged at $17,000 \times g$ for $15 \mathrm{~min}$ at $4^{\circ} \mathrm{C}$. Protein content was quantified by Bradford reagent (Bio-Rad). Protein lysates were analyzed on 4-12\% NuPAGE gels (Invitrogen) or 6\% SDS-PAGE gels, transferred to PVDF membranes, and immunoblotted using HRP-conjugated secondary antibodies and ECL West Pico detection system (Thermo Scientific).

Coimmunoprecipitation. Dissected mouse retinas were homogenized in lysis buffer (1\% Nonidet P-40, 2 mM EDTA, and 20 mM HEPES, pH 7.4 , supplemented with protease inhibitor cocktail) by rotating at $4^{\circ} \mathrm{C}$ for $45 \mathrm{~min}$. Homogenates were cleared by centrifugation at 17,000 $\mathrm{g}$ for 20 min at $4^{\circ} \mathrm{C}$. For coimmunoprecipitation, retinal lysates or transfected HEK cell lysates were precleared by incubating with $12 \mu$ l Dynabeads protein $\mathrm{G}$ (Invitrogen) at $4^{\circ} \mathrm{C}$ for $1 \mathrm{~h}$. Precleared lysates were incubated with 2-5 $\mu$ g of anti-GPR179 or anti-Flag antibodies overnight at $4^{\circ} \mathrm{C}$ on an orbital rocker. Forty five microliters of Dynabeads protein $G$ was added and incubated for $1-2 \mathrm{~h}$ at $4^{\circ} \mathrm{C}$. Dynabeads were collected and washed four times with Tris-buffered saline containing $0.3 \%$ Tween 20 . Protein complexes were eluted with $40 \mu \mathrm{l}$ of $4 \times$ LDS loading buffer by incubation at $70^{\circ} \mathrm{C}$ for $10 \mathrm{~min}$, separated by SDS-PAGE, and analyzed by immunoblotting.

ERG. ERG studies were conducted in Cleveland, $\mathrm{OH}$, and at the University of Louisville (UofL). Animals were dark adapted overnight and anesthetized with ketamine $(80 \mathrm{mg} / \mathrm{kg})$ and xylazine $(16 \mathrm{mg} / \mathrm{kg})$. Eye drops were used to dilate the pupil ( $1 \%$ tropicamide and $2.5 \%$ phenylephrine $\mathrm{HCl})$ and to anesthetize the corneal surface (1\% proparacaine $\mathrm{HCl}$ ). ERGs were recorded using stainless steel (strobe flash) or gold (variable duration) electrodes contacting the corneal surface wetted with $1 \%$ methylcellulose. Platinum needle electrodes in the cheek and tail serve as reference and ground, respectively. Mice were tested using two 
ERG recording protocols, which used either a strobe flash or variable duration stimuli. Strobe flash ERGs were recorded using an LKC UTAS E-3000 signal averaging system. Stimuli ranged in luminance from -3.6 to $1.4 \log \mathrm{cd} \mathrm{s} / \mathrm{m}^{2}$. At UofL the LKC system also was used to record variable duration flash ERGs, whereas in Cleveland a Diagnosys Espion system was used. Both systems used an approximately $-1.2 \mathrm{log} \mathrm{cd} / \mathrm{m}^{2}$ flash whose duration ranged from 10 to $1000 \mathrm{~ms}$. Because of slight variations in flash levels and procedures between the systems, all ERG data were normalized to WT data from the individual institutions.

Retinal slice preparation and whole-cell, patch-clamp recording. Mice were anesthetized with an intraperitoneal injection of Ringer's solution containing ketamine/xylazine (127/12 mg/kg, respectively) and killed by cervical dislocation. The eyes were enucleated and the retinas removed and placed in fresh Ames solution (Sigma-Aldrich). The retina was adhered to nitrocellulose paper (Millipore) and then sliced perpendicular to the retinal layers using a tissue slicer. The slices were then placed in a recording chamber. Recording electrodes were pulled from borosilicate glass (FHC) on a P-97 Flaming/Brown Micropipette Puller (Sutter Instruments). Electrode resistance measured between 6 and $9 \mathrm{M} \Omega$. Glass electrodes were filled with intracellular solution that contained Csgluconate solution ( $20 \mathrm{~mm} \mathrm{CsCl}, 107 \mathrm{~mm} \mathrm{CsOH}, 107 \mathrm{~mm}$ D-gluconic acid, $10 \mathrm{~mm}$ NaHEPES, $10 \mathrm{~mm}$ BAPTA, $4 \mathrm{~mm}$ ATP, and $1 \mathrm{~mm}$ GTP). The intracellular solution contained $1 \%$ sulforhodamine to visualize the cell and classify its morphology (Ghosh et al., 2004). Rod BC somas were targeted for whole-cell, patch-clamp recording. A 2-4 G $\Omega$ seal was created on the cell body and cells with an input resistance $\sim 1 \mathrm{G} \Omega$ and access resistance $<25 \mathrm{M} \Omega$ were used for recording. The recording chamber was maintained at $34-35^{\circ} \mathrm{C}$.

To block inhibitory inputs, Ames solution was supplemented with the following: $1 \mu \mathrm{M}$ strychnine, $100 \mu \mathrm{M}$ picrotoxin, and $50 \mu \mathrm{M}$ 6-tetrahydropyridin-4-yl methylphosphinic acid. L-AP4 $(4 \mu \mathrm{M})$ was added to the bath solution to saturate mGluR6 receptors. The mGluR6 receptor antagonist $\alpha$-cyclopropyl-4-phosphonophenylglycine (CPPG) was dissolved in Ames medium to a working concentration of $0.6 \mathrm{~mm}$ or $3 \mathrm{~mm}$. CPPG was applied by pressure application using a Picospritzer II (Parker Instrumentation) onto the rod BC dendritic tips in the OPL. In separate experiments, capsaicin $(10 \mu \mathrm{M})$, a TRPM1 agonist, was puffed onto the rod $\mathrm{BC}$ dendrites to gate the opening of the TRPM1 channel. Reagents were purchased from Sigma-Aldrich, except for L-AP4, CPPG, and capsaicin, which were purchased from Tocris Bioscience.

Voltage-clamp protocols. Rod BC responses were recorded via a Multiclamp 700A amplifier with a Digidata 1440A digitizer (MDS Analytical Technologies) and filtered at $2.4 \mathrm{kHz}$ with a four-pole Bessel low-pass filter, sampled at $10 \mathrm{kHz}$. Off-line a $20 \mathrm{~Hz}$ eight-pole Bessel low-pass filter was applied to the data. Clampex 10.2 software (MDS Analytical Technologies) was used to generate command outputs and acquire and analyze analog whole-cell current. Rod BCs were voltage clamped at $+50 \mathrm{mV}$ (Nawy, 2004; Shen et al., 2009). CPPG was puffed at rod BC dendrites for $200 \mathrm{~ms}$ and $1 \mathrm{~s}$. For capsaicin experiments $1 \mathrm{~s}$ puffs were applied. Three to five responses were recorded from each cell and then averaged. Variance and standing current were measured across the first $1.5 \mathrm{~s}$ of the recording for each rod BC. Off-line analyses of data were performed using Clampfit 10.2. Prism 5.04 software (GraphPad Software) was used to perform two-way repeated-measures ANOVAs, two-way ANOVAs, one-way ANOVAs, or $t$ tests as suited for the necessary comparison. Statistical significance $=p<0.05$

\section{Results}

The localization of mGluR6, TRPM1, and NYX to the DBC dendritic tips is independent of GPR179 expression

Since GPR179 is critical to localization of RGS7 and RGS11 (Orlandi et al., 2012), we examined if it plays a similar role for other DBC cascade proteins. We compared expression and localization of mGluR6, the receptor that initiates DBC signaling and TRPM1, the channel that is ultimately gated by the cascade in WT and $G$ pr $179^{n o b 5}$ retinas. To examine nyctalopin expression, a protein critical to expression/localization of TRPM1 (Pearring et al., 2011), we crossed the Gpr $179^{n o b 5}$ allele onto the Tg EYFP-Nyx
A

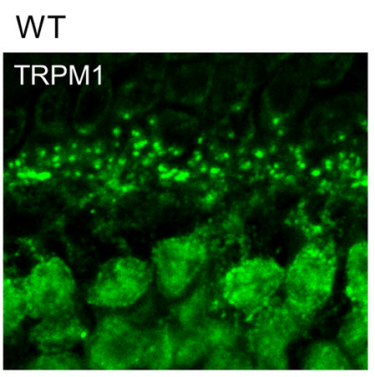

Gpr179nob5
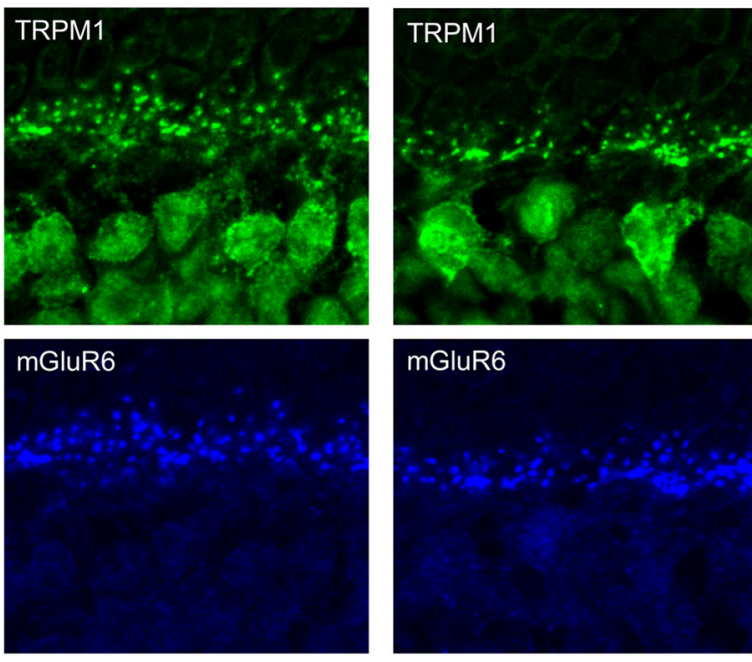

OPL

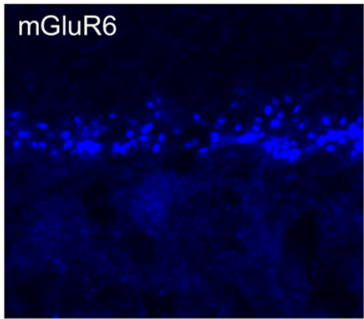

OPL
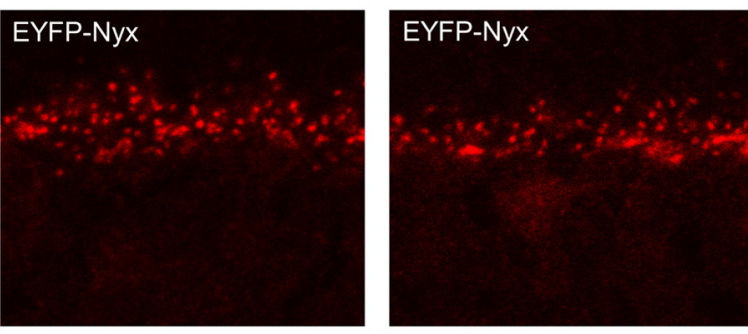

INL
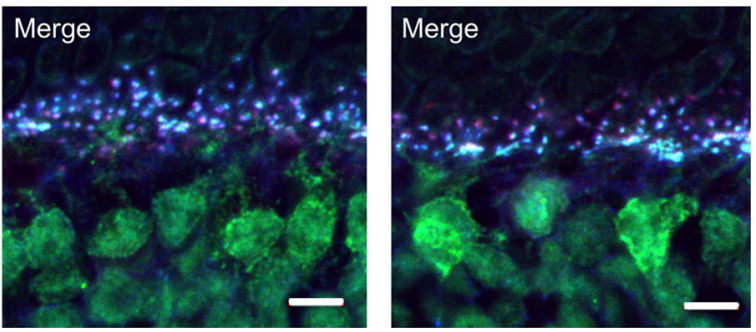

OPL

INL

Figure 1. mGluR6, TRPM1, and NYX expression is independent of GPR179 expression. Representative confocal images of cross sections of the OPL and inner nuclear layer (INL) of WT (A) and $G p r 17 g^{\text {nob5 }}(\boldsymbol{B})$ retinas reacted with antibodies to TRPM1 (green), mGluR6 (blue), and EYFP-Nyx (red). The merged images (bottom) show that expression patterns are similar in WT and in Gpr179 ${ }^{\text {nob5 }}$ retinas and that TRPM1, mGluR6, and nyctalopin expression colocalize at the dendritic tips of DBCs. Scale bars: $5 \mu \mathrm{m}$.

mice that express EYFP tagged nyctalopin on a WT background (Gregg et al., 2007). The retinal expression patterns of TRPM1, mGluR6, and EYFP-Nyx proteins are indistinguishable between mice with WT alleles at the Gpr179 locus and Gpr179 ${ }^{\text {nob5 }}$ mice (Fig. 1, WT). The merged images in triple-labeled retinal sections show that TRPM1, mGluR6, and nyctalopin expression overlaps on the dendritic tips of the DBCs.

To determine the dependence of GPR179 expression on OPL localization of mGluR6, nyctalopin, or TRPM1, we reacted retinal sections from WT and mutant mice: $\mathrm{Grm}^{-/-}$(Grm6 encodes mGluR6), $N y x^{n o b}$, and Trpm1 $1^{-/-}$with antibodies to GPR179 (Peachey et al., 2012b) and used the lectin PNA, to delineate the cone pedicles in the OPL. The pattern of GPR179 expression is indistinguishable across all four mouse strains (Fig. $2 A-D$ ). As expected (Peachey et al., 2012b), GPR179 expression is absent in the $G \operatorname{pr} 179^{\text {nob5 }}$ retina (Fig. 2E).

Although not evident in these images (Figs. 1,2), we observed subtle differences in the level of GPR179 expression across these 


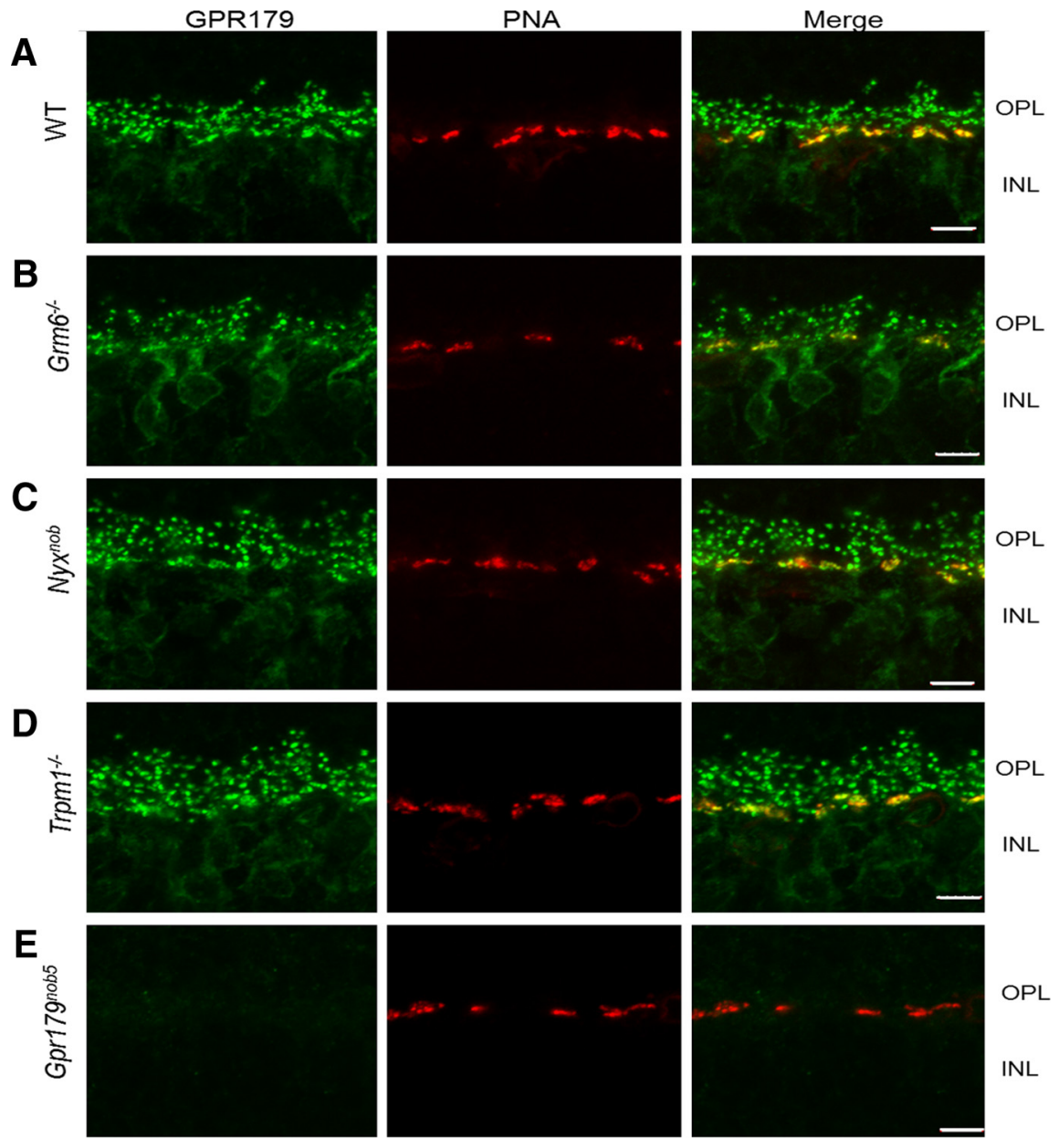

Figure 2. GPR179 expression at the dendritic tips of the DBC s is independent of mGluR6, TRPM1, and nyctalopin expression. Representative confocal images of cross sections of the OPL and inner nuclear layer (INL) of WT and a series of mutant mouse retinas reacted with an antibody to GPR179 (green) and the cone pedicle marker, PNA (red). $\boldsymbol{A}$, In all retinas except Gpr $179^{\text {nob5 }}$, expression of GPR179 (green puncta) is found both at the rod BC dendritic tips and colocalized with PNA (yellow puncta in merged images). $\boldsymbol{B}-\boldsymbol{D}$, GPR179 expression is localized at the dendritic tips of DBCs even in the absence of expression of mGluR6 (B), nyctalopin $(\boldsymbol{C})$, and TRPM1 (D). As shown here (E) and previously (Peachey et al., 2012b), GPR179 expression is absent from Gpr179 ${ }^{\text {nob5 }}$ mouse retina. Scale bars: $5 \mu \mathrm{m}$.

mutants. To quantify protein expression levels of GPR179 relative to WT, we used Western blotting with retinal lysates from each mutant (Fig. $3 A, B$ ). As expected, GPR179 is absent in Gpr $179^{n o b 5}$ retinas (the negative control) and is decreased $\sim 50$ and $20 \%$ in $\mathrm{Grm6}^{-/-}$and $\operatorname{Trpm} 1^{-/-}$retinas, respectively. We also quantified TRPM1 expression levels in WT, Gpr179 ${ }^{\text {nob5 }}$, and $\mathrm{Grm}^{-/-}$retinas (Fig. 3C,D). TRPM1 expression is absent in $\operatorname{Trpm} 1^{-/-}$retinas (the negative control), decreased $\sim 30 \%$ in Gpr $179^{\text {nob5 }}$ retinas, and similar to WT in $\mathrm{Grm6}^{-/-}$retinas. In summary, our data show that GPR179 is localized correctly in the OPL independent of mGluR6, TRPM1, and nyctalopin and that the localization of these proteins is independent of GPR179, although expression levels may be somewhat altered as has been reported for several cascade components by others (Cao et al., 2009, 2012; Zhang et al., 2010; Pearring et al., 2011; Dhingra et al., 2012; Orlandi et al., 2012).

GPR179 and TRPM1 are part of the same protein complex

We and others have shown a physical interaction between TRPM1 and nyctalopin (Cao et al., 2011; Pearring et al., 2011) and between GPR179 and RGS7 and RGS11 (Orlandi et al., 2012). At the resolution of the confocal microscope, GPR179 and
TRPM1 colocalize at the DBC dendritic tips (Fig. 3E), suggesting that they may interact. Using an affinity purification by immunoprecipitation (IP) approach and antibodies to GPR179, we immunoprecipitated protein complexes from WT mouse retinal lysates and then identified the coimmunoprecipitated proteins using mass spectrometry. Each experiment resulted in the identification of hundreds to thousands of peptides that could be mapped to hundreds of proteins. IP with antibodies to GPR179 yielded 121 peptides whose identity matched GPR179 and gave a coverage of $55 \%$. Two other peptides were identified as TRPM1 (2\% coverage). IP with antibodies to TRPM1 yielded 48 peptides that matched TRPM1 (57\% coverage) and 12 that matched GPR179 (9\% coverage). As a negative control for the specificity of the antibodies, we performed the identical IP with a nonspecific IgG. None of the peptides in the resulting dataset matched GPR179 or TRPM1, or any other known component of the DBC signal transduction cascade. Additional negative controls included IP with GPR179 antibodies using GPR $179^{\text {nob5 }}$ retinal lysate and IP with TRPM1 antibodies using $\operatorname{Trpm} 1^{-/-}$retinal lysate. Neither TRPM1 nor GPR179 peptides were identified in the resulting datasets. These data indicate our IP results are specific and that GPR179 and TRPM1 are part of the same protein complex and likely directly interact.

To corroborate the mass spectrometry results that GPR179 and TRPM1 interact directly, we performed IP using lysates from HEK293T cells cotransfected with GPR179 and FLAG-TRPM1 expression vectors (Pearring et al., 2011) as well as WT mouse retinal lysates (Fig. $3 F, G$ ). Western blot analyses of singly (Fig. 3F, lanes 1,2) and doubly (Fig. 3F, lane 3) transfected HEK293T cell lysates show that both proteins were expressed. IP with the FLAG antibody (Fig. 3F, lanes 4-6) precipitated FLAG-TRPM1 only in singly transfected cell lysates (Fig. $3 F$, lanes 4,5 ) and precipitated both GPR179 and FLAG-TRPM1 from double transfected cell lysates (Fig. 3F, lane 6), indicating protein interaction. To control for possible protein interaction during the lysis procedure, we singly transfected either GPR179 or FLAG-TRPM1 into different HEK293T cell cultures, lysed the cells, and mixed their lysates. IP with the FLAG antibody did not precipitate GPR179 from the mixture (data not shown), supporting our conclusion that GPR179 and TRPM1 interact directly.

We repeated the IP experiments using WT and Gpr179 $19^{\text {nob5 }}$ retinal lysates (Fig. 3G). Both GPR179 and TRPM1 were present in WT retinal lysate (Fig. 3G, lane 1). IP of WT retinal lysates with the GPR179 antibody (Fig. 3G, lanes 3,5) coprecipitated TRPM1 and GPR179 (Fig. 3G, lanes 3,5). As controls, we repeated the IP experiments using retinal lysates from $G \operatorname{pr} 179^{\text {nob5 }}$ (Fig. 3G, lane 4) or $\operatorname{Trpm} 1^{-/-}$(Fig. 3G, lane 6). Neither GRP179 nor TRPM1 were present in precipitates from the $G$ pr $179^{\text {nob5 }}$ retinas (Fig. 3G, 
A
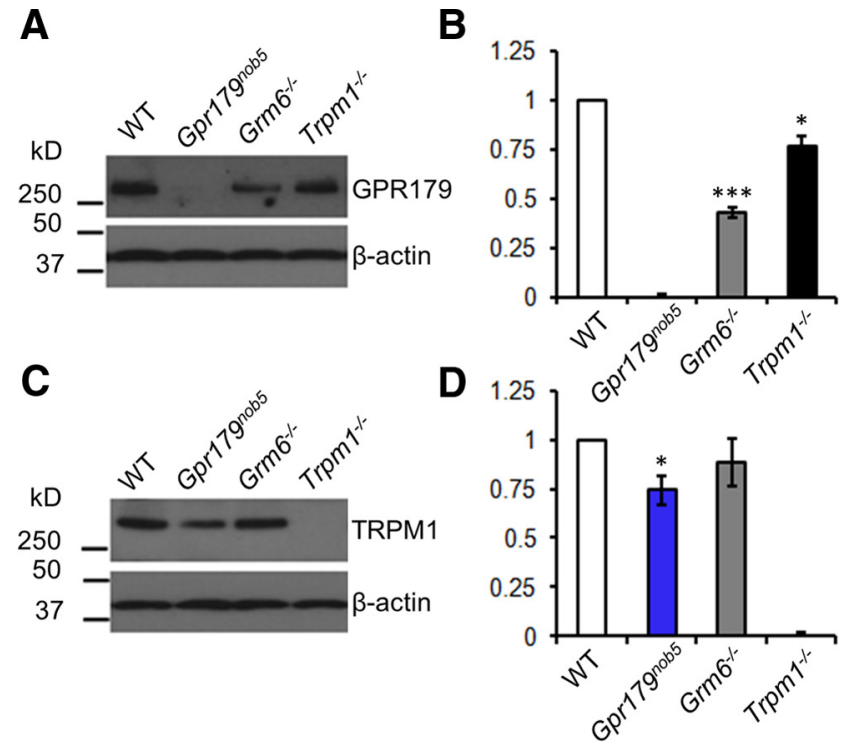

\section{E}
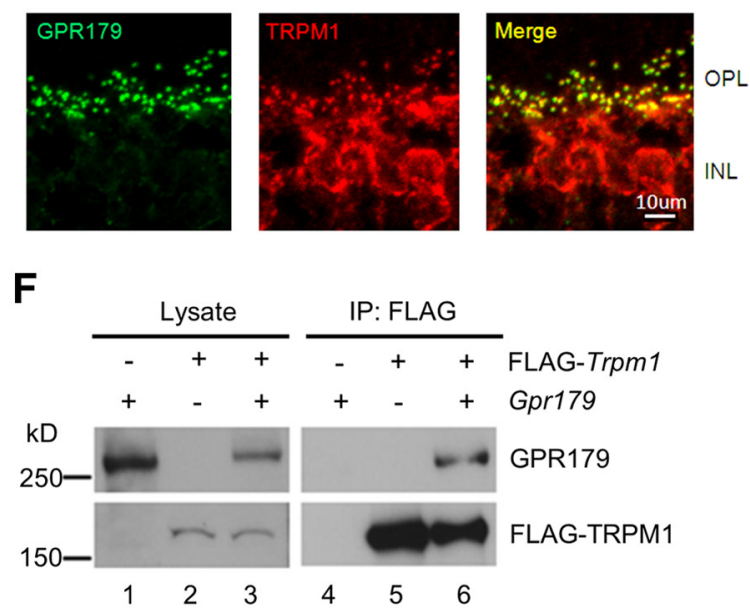

G

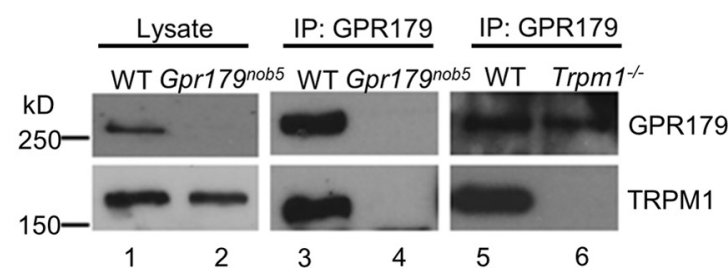

Figure 3. GPR179 and TRPM1 proteins interact. Western blots of total retinal lysates probed with antibodies to (A) GPR179 and (C) TRPM1 (top). Each blot was reprobed with antibodies to $\beta$-actin (bottom) to determine total protein and for use as an internal standard. Band intensities were analyzed and quantified with $\mathrm{NIH}$ ImageJ software and normalized to $\beta$-actin expression level in the same sample. The histograms $(\boldsymbol{B}, \boldsymbol{D})$ plot the mean expression ( \pm SEM) from four experiments on independent retina samples. $\boldsymbol{B}, \mathrm{GPR} 179$ expression was lower in $\mathrm{Grm}^{-/-}$ and $\mathrm{Trpm} 1^{-/-}$retinas compared with WT. D, TRPM1 expression was similar to WT in Grm6 $6^{-1-}$ and in Gpr179 ${ }^{\text {nob5 }}$ retinas. Statistical analyses ( $t$ test) were performed before normalization. Error bars represent $\mathrm{SE} ;{ }^{*} p<0.05,{ }^{* * *} p<0.001$. E, GPR179 and TRPM1 colocalize on the dendritic tips of DBCs. Representative confocal images of cross sections of the OPL and inner nuclear layer (INL) of WT retina reacted with antibodies to TRPM1 (green) and GPR179 (red). The merged image shows that TRPM1 and GPR179 expression colocalize at the dendritic tips of DBCs. Scale bar, $5 \mu \mathrm{m}$. $\boldsymbol{F}$, Western blot of lysate from HEK293T cells transfected with plasmids expressing GPR179 (lane 1), FLAG-TRPM1 (lane 2), or both (lane 3) and probed with antibodies to GPR179 (top row) and FLAG (bottom row). The presence of a specific expression construct is indicated by " +" above the lane on the blot. Lysates from HEK293T samples (lanes 1-3) were immunoprecipitated with antibodies to GPR179 and the precipitates analyzed by Western blotting (lanes 4-6), using antibodies to GPR179 (top row) or TRPM1 (bottom row). These data lane 4). Only GPR179 was present in precipitates from $\operatorname{Trpm} 1^{-/-}$ retinas (Fig. 3G, lane 6). Our combined mass spectrometry and IP results support the conclusion that GPR179 and TRPM1 are part of the same synaptic complex and interact directly.

\section{Gpr179 ${ }^{\text {nob }}$ mice have ERG b-waves absent in other cCSNB} mouse models

Previous comparisons of the ERG responses of WT and Gpr $179^{n o b 5}$ showed a significant reduction in the Gpr $179^{n o b 5}$ $\mathrm{b}$-wave and we interpreted this result as a no b-wave phenotype (Peachey et al., 2012b). Although the positive polarity b-waves of the ERG responses from Gpr $179^{\text {nob5 }}$ and Trpm1 $1^{-/-}$mice compared with WT (Fig. 4A) appeared to be completely missing, upon closer inspection, we found a b-wave-like response, albeit small $(\sim 15-20 \mu \mathrm{V})$, to low luminance flashes $(-3.6,-2.4 \log \mathrm{cd}$ $\left.\mathrm{s} / \mathrm{m}^{2}\right)$ that was consistently present in $G \operatorname{pr} 179^{\text {nob5 }}$ but absent in Trpm $1^{-1-}$ mice (Fig. $4 B$; $t$ test; $p<0.001$ ). We missed this response previously because it is evident only when the a-wave and slow PIII components are small in amplitude.

Given the small ERG response and a previous observation that a small response could be evoked in $R G S 7^{-/-} / R G S 11^{-/-}$rod BCs to a luminance step (Cao et al., 2012), we examined whether the response could be enhanced by long duration (10-1000 ms), full-field stimuli at $-1.2 \log \mathrm{cd} / \mathrm{m}^{2}$. To these stimuli WT responses were dominated by the b-wave (Fig. $4 C$ ), which grew in amplitude as stimulus duration increased, reaching a plateau at $\sim 50 \mathrm{~ms}$ (Fig. 4D). The same stimuli evoked slow b-waves in both Gpr179 ${ }^{n o b 5}$ and in $R G S 7^{-1-} / R_{G S 11^{-1-}}$ mice, which also increased in amplitude with stimulus duration and reached a plateau at $\sim 500 \mathrm{~ms}$ (Fig. $4 D$ ). Compared with WT, the b-wave amplitudes of Gpr $179^{n o b 5}$ and $R G S 7^{-1-} / R G S / 11^{-/-}$mice were significantly smaller (two-way ANOVA; $p<0.001$ for both). In contrast, we were not able to record a b-wave from $\operatorname{Trpm} 1^{-1-}$ mice (Fig. $4 C, D$ ) or from two other mouse models of CCSNB, $N y x^{n o b}$, and $\mathrm{Grm}^{n o b 3}$ (data not shown). These results suggest that an mGluR6-mediated modulation of TRPM1 remains despite the absence of GPR179 and/or RGS7 and RGS11. Further, while RGS7 and RGS11 are both absent from the dendrites of GPR179 ${ }^{\text {nob }}$ mice (Cao et al., 2012), GPR179 is expressed normally in the $\mathrm{RGST}^{-/-} / \mathrm{RGS}_{1} 1^{-/-}$mice (Fig. $4 E$ ).

\section{GPR179 sets the sensitivity of the mGluR6 cascade that modulates TRPM1}

Our observations and a previous report show that both mGluR6 and TRPM1 proteins are expressed in the OPL of Gpr179 ${ }^{\text {nob5 }}$ (Fig. 1) and $R G S 7^{-/-} / R G S / 11^{-/-}$(Cao et al., 2012; Fig. 2) retina. The presence of a small ERG b-wave in these mice (Fig. 4) suggests that the mGluR6 and its cascade maintain the capacity to gate the TRPM1 channel, although the sensitivity is significantly reduced. To examine the capacity of the cascade to gate the channel, we used an approach first described by Nawy (2004) that pharmacologically mimics the mGluR6 cascade activation by light. Retinal slices were bathed in $4 \mu \mathrm{M} \mathrm{L}-\mathrm{AP} 4$ to maximally activate the

$\leftarrow$

show that TRPM1 is coimmunoprecipitated with GPR179 (lane 6). G, Western blot of retinal lysates from WT (lane 1) and Gpr179 ${ }^{\text {nob5 }}$ (lane 2) probed with antibodies for presence of GPR179 (top row) or TRPM1 (bottom row). Western blots of proteins coimmunoprecipitated with antibodies to GPR179 from WT (lanes 3,5), Gpr179 $9^{\text {nob5 }}$ (lane 4), and Trpm $1^{-/-}$(lane 6) probed for GPR179 (top row) or TRPM1 (bottom row). IP with GPR179 antibody from retinal lysates of $G$ Gr179 $9^{\text {Nob5 }}$ and $T r p m 1^{-1-}$ mice served as controls for nonspecific binding. These data were representative of at least three independent experiments using independent retinal samples. Data show that GPR179 and TRPM1 coimmunoprecipitate (lanes 3,5). 

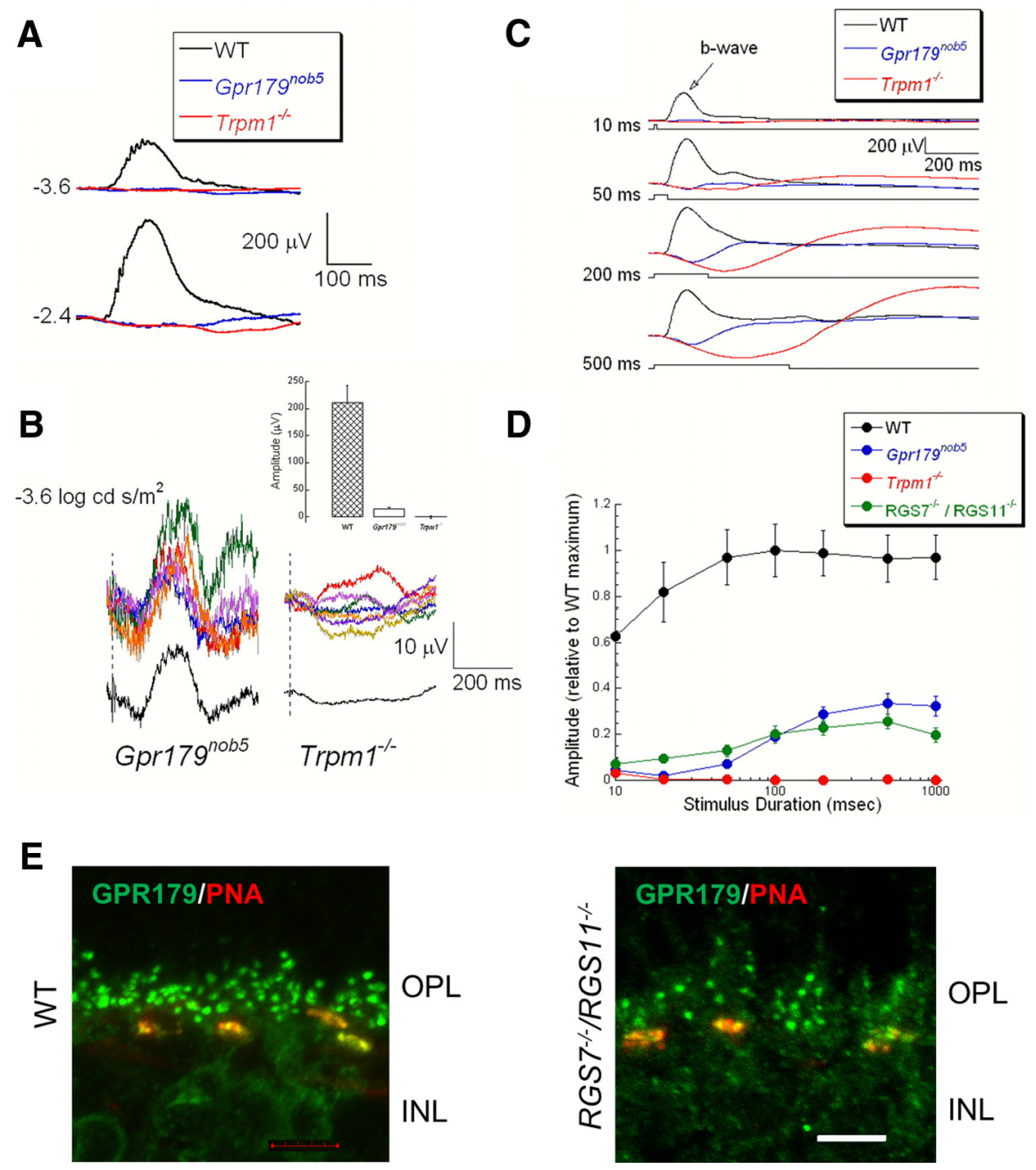

Figure 4. Gpr179nob5 rod ERGs have a small b-wave. A, Representative rod ERGs recorded from WT (black), Gpr179nob5 (blue), and $\operatorname{Trpm} 1^{-1-}$ (red) mouse retinas to strobe flash stimuli presented to the dark-adapted retina. Note that the positive polarity

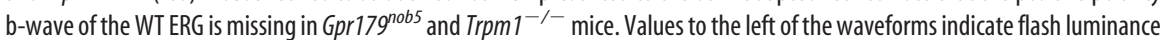
in $\log \mathrm{cd} \mathrm{s} / \mathrm{m}^{2}$. B, ERG responses obtained from Gpr179 ${ }^{\text {nob5 }}$ and $\operatorname{Trpm} 1^{-1-}$ mice to a $-3.6 \log \mathrm{cd} \mathrm{s} / \mathrm{m}^{2}$ flash. Colored traces indicate the responses from five different $G$ pr $179^{\text {nob5 }}$ mice (left) and seven different $T r p m 1^{-\prime-}$ mice (right). The offset black trace on each side is the average of all mice. Inset, Histograms show average ( \pm SEM) $b$-wave amplitude (difference between prestimulus baseline and the largest positive deviation from the baseline recorded between 100 and $300 \mathrm{~ms}$ after flash presentation) of responses shown in $\boldsymbol{B}$. Note: In Gpr179 nob mice there is a response that is absent in $\operatorname{Trpm} 1^{-1-}$ mice. C, Representative ERG responses recorded from WT (black), Gpr179 ${ }^{\text {nob5 }}$ (blue), and $\operatorname{Trpm} 1^{-1-}$ (red) mice to $-1.2 \mathrm{log} \mathrm{cd} / \mathrm{m}^{2}$ stimuli of increasing duration (top to bottom; and, indicated by the stimulus trace below each set of waveforms). Note: As stimulus duration increases, a slow positive wave becomes apparent in $\mathrm{Gpr} 179^{\text {nobs }}$ mice that is absent in $\mathrm{Trpm} 1^{-/-}$mice. Waveforms indicate the average of WT $(n=3), \operatorname{Gpr} 179^{\text {nob5 }}(n=12)$, and $\operatorname{Trpm} 1^{-/-}(n=7)$ mice. D, Average ( \pm SEM) b-wave amplitude evoked by flash stimuli of different durations for the same mice. Note: The amplitude of the $G$ pr $179^{\text {nob5 }}$ response increases across a range of flash durations $(20-500 \mathrm{~ms})$, whereas WT response amplitudes are stable $(\geq 20 \mathrm{~ms})$ and $\operatorname{Trpm} 1^{-1-}$ mice lack a response at all durations. Measures are normalized to WT maxima at Cleveland or UofL. Results for mutant mice are normalized to WT at each institution. Averages ( \pm SEM) for 12 Gpr $179^{\text {nob5 }}, 7 \mathrm{Trpm} 1^{-1-}$, or $5 \mathrm{RGS} 7^{-1-} / \mathrm{RGS} 11^{-1-}$ mice. E, GPR 179 is expressed on the dendritic tips of $R G S 7^{-1-} / R G S 11^{-1-}$ DBCs. Representative confocal images of cross sections of the OPL and inner nuclear layer (INL) of WT retina reacted with antibodies to GPR179 (green) and the cone terminal marker PNA (red). The images show the merge therefore the cone terminals appearyellow because GPR179 is expressed on cone DBCs and PNA colocalize at that location. The green puncta represent the staining of GPR179 on the dendritic tips of rod BCs. Scale bar, $5 \mu \mathrm{m}$.

mGluR6 cascade and close TRPM1 channels and CPPG was exogenously applied (puffed) onto the rod BC dendrites to deactivate the cascade and open the TRPM1 channel. We used the same approach and puffs of capsaicin, which is a TRPM1 channel agonist and directly gates the channel. For all recordings, we held rod BCs at $+50 \mathrm{mV}$ to minimize rundown and, as a consequence, both CPPG and capsaicin puffs evoked outward currents (Figs. 5, 6).
Puffs of CPPG (0.6 mM; an mGluR6 antagonist) onto the dendritic terminals of synaptically isolated WT rod BCs evoked a robust current whose amplitude was similar regardless of puff duration (200 ms or $1 \mathrm{~s}$ duration; Fig. 5 A; two-way ANOVA: $p>0.05)$. As a result, in our comparisons WT responses were combined (Fig. 5B). The responses of Gpr $179^{\text {nob5 }}$ and $R G S 7^{-/-} / R G S 11^{-/-}$rod BCs to 200 ms CPPG puffs were similar but significantly smaller than WT (Fig. $5 B$;

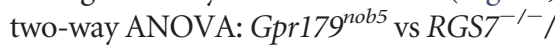
$R G S 11^{-1-}, p>0.05 ; G p r 179^{\text {nob5 }}$ vs WT, $p<0.001 ; R G S 7^{-1-} / R_{G S 11^{-1-}}$ vs WT, $p<0.001)$. In contrast to WT, increasing puff duration to $1 \mathrm{~s}$ produced significant increases in both Gpr179 nob5 and $R G S 7^{-1-} / R_{G S 11^{-1-}}$ rod BC responses (Fig. $5 A, B$; two-way ANOVA: $p<0.001$ for both comparisons), although again amplitudes were significantly smaller than WT (Fig. $5 A, B$; two-way ANOVA: $p<0.001$ for both comparisons). Increasing the concentration of CPPG to $3 \mathrm{~mm}$ had minimal impact on the WT response (Fig. 5C,D), indicating that the mGluR6 cascade is maximally activated by $0.6 \mathrm{~mm}$ puffs for 200 ms. Increasing CPPG concentration to $3 \mathrm{~mm}$ evoked similar re-

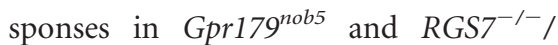
$R G S 11^{-/-}$rod BCs independent of puff duration, although responses were always significantly smaller than WT (Fig. 5C,D;

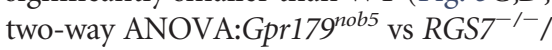
$R G S 11^{-1-} 200 \mathrm{~ms}$ and $1 \mathrm{~s}, p>0.05$; $G p r 179^{n o b 5}$ vs WT $200 \mathrm{~ms}$ and $1 \mathrm{~s}, p<$ $0.001 ; R G S 7^{-/-} / R_{G S 11^{-/-}}$vs WT $200 \mathrm{~ms}$ and $1 \mathrm{~s}, p<0.001)$. Together these results suggest that in rod BCs TRPM1 can be gated even when GPR179 expression is absent. The specific role of GPR179 cannot be determined with the reagents at hand, because the effects on cascade sensitivity could be because of its close interaction with TRPM1. However, the fact that it also is required for localization of the RGS complex confounds a simple conclusion.

Because TRPM1 is expressed in both Gpr179 nob5 and in $R G S 7^{-1-} / R_{G S 11^{-/-}}$ rod BCs, we assumed that the capsaicinevoked current would be mediated by TRPM1. To test this idea, we compared direct activation of the TRPM1 channel

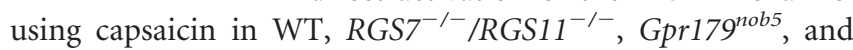
$\operatorname{Trpm} 1^{-1-}$ rod BCs. As observed previously (Shen et al., 2009), capsaicin evokes robust responses in WT rod BCs (Fig. 6A,B) and the capsaicin-evoked current in $R G S 7^{-/-} / R G S 11^{-/-}$and WT rod BCs were not significantly different (one-way ANOVA: WT vs $\left.R G S 7^{-1-} / R G S 11^{-/-}, p>0.05\right)$. In contrast, the capsaicinevoked current in Gpr179 ${ }^{n o b 5}$ rod BCs was significantly smaller 
A

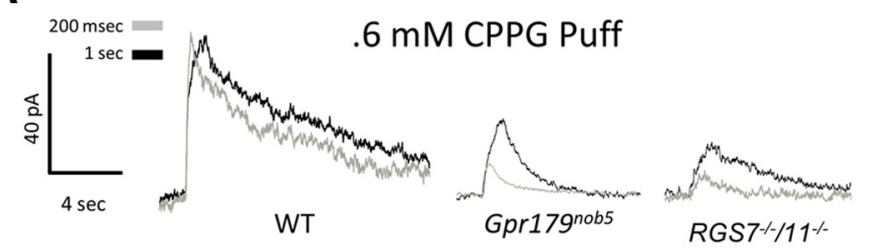

B

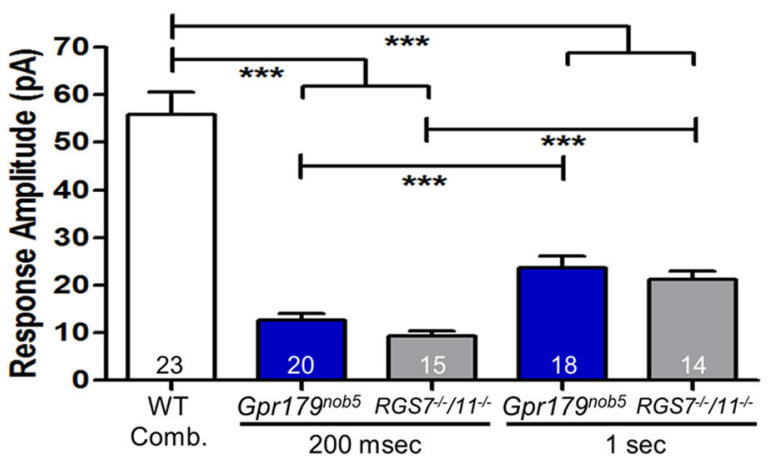

C

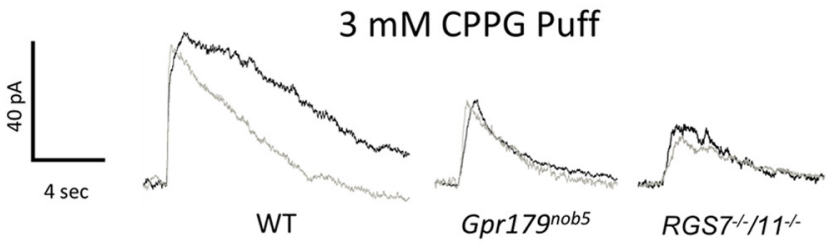

D

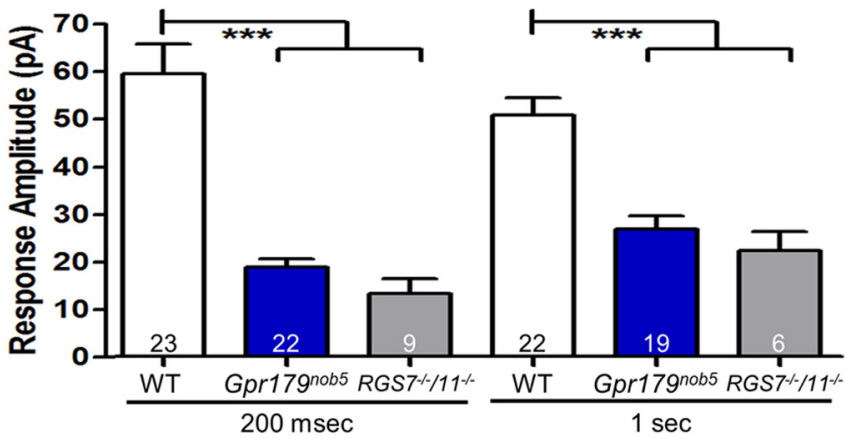

Figure 5. A small amplitude, concentration-dependent CCPG response in Gpr $179^{\text {nobs }}$ and $R G S 7^{-/-} / R G S 11^{-/-}$rod BCs. A, Representative voltage-clamp responses of WT, Gpr179 $9^{\text {nobs }}$, and $R G S 7^{-/-} / R G S 11^{-1-}$ rod BCs evoked by puff application of the mGluR6 antagonist, CPPG $(0.6 \mathrm{~mm}$ for $200 \mathrm{~ms}$ or $1 \mathrm{~s})$. B, Histogram compares the average peak response amplitudes ( \pm SEM) of WT,

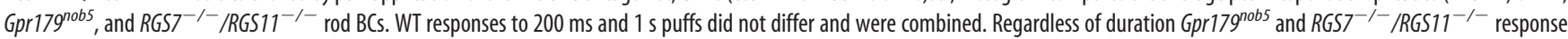
amplitudes were significantly smaller than WT, although response amplitudes of rod BCs from both mutants significantly increase when puff duration increased from $200 \mathrm{~ms}$ to $1 \mathrm{~s}$. C, Representative voltage-clamp responses of WT, Gpr $179^{\text {nob }}$, and $R G S 7^{-/-} / R G S 11^{-/-}$rod BCs evoked by puff application of $3 \mathrm{~mm} \mathrm{CPPG} \mathrm{for} \mathrm{either} 200 \mathrm{~ms}$ or $1 \mathrm{~s}$. D, Histogram compares the average peak response ( \pm SEM) amplitudes of WT, Gpr $179^{\text {nobs }}$, and $R G S 7^{-1-} / R G S 11^{-1-}$ rod BCs. WT responses did not change with increased concentration or puff duration of CPPG (200 ms to $\left.1 \mathrm{~s}\right)$. Regardless of duration Gpr $179^{\text {nobs }}$ and $R G S 7^{-1-} / R_{G S} 11^{-1-}$ response amplitudes were significantly smaller than WT. The increased puff duration did not produce larger response amplitudes in either Gpr $179^{\text {nobs }}$ or $R G S 7^{-/-} / R_{G S 11^{-/-}}$rod BCs, suggesting that they were saturated under these conditions (two-way ANOVA ${ }^{* * *} p<0.001$ ).

A

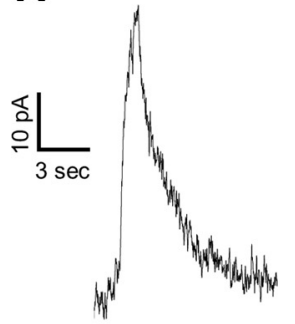

WT

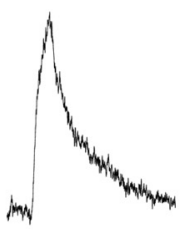

RGS7 $\% / 11 \%$

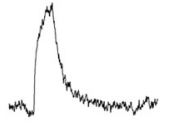

Gpr179nob5

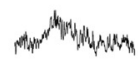

TrpM1-
B

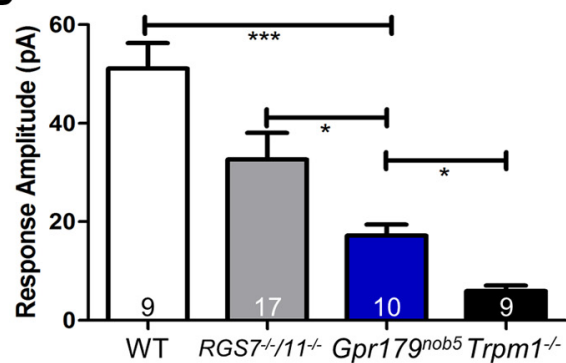

Figure 6. Capsaicin-evoked TRPM1 responses are normal in $R G S 7^{-1-} / R G S 11^{-1-}$ and decreased in Gpr $179^{\text {nob5 }}$ rod BCS. A, Representative voltage-clamp responses ofWT, RGS7 ${ }^{-/-} / R G S 11^{-/-}$, Gpr179nobs , and TRPM1 ${ }^{-1-}$ rod BCs evoked by a $1 \mathrm{~s}$ puff of the TRPM1 channel agonist, capsaicin (10 $\left.\mu \mathrm{M}\right)$. B. Histogram compares the average peak response amplitudes ( \pm SEM) of WT,

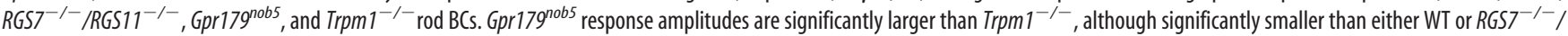
$R G S 11^{-1-} \operatorname{rod} B C s$. The responses from $R G S 7^{-1-} / R G S 11^{-1-}$ rod BCs are the same as WT. The number of rod BCs in each experimental group is shown within each bar of the histograms (one-way ANOVA, $\left.{ }^{*} p<0.05 ;{ }^{* * *} p<0.001\right)$.

than either WT or $R G S 7^{-/-} / R G S 11^{-/-} \operatorname{rod} \mathrm{BCs}$ (one-way

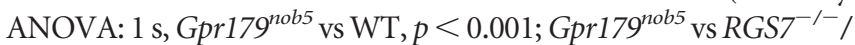
$\left.R G S 11^{-/-}, p<0.05\right)$. This response also was significantly larger than the capsaicin-evoked current in $\operatorname{Trpm} 1^{-/-}$rod BCs, which are barely measurable above background noise (one-way ANOVA: Gpr179 ${ }^{n o b 5}$ vs Trpm1 $\left.1^{-/-}, p<0.05\right)$. These results indicate that it is the presence of GPR179 in both WT and $R G S 7^{-/-}$/ $R G S 11^{-/-}$DBCs that allows the TRPM1 channel to be efficiently gated by capsaicin, whereas its absence leads to a TRPM1 channel whose sensitivity to direct gating is significantly reduced.
Given this result, we examined the open probability of TRPM1 channels and compared the magnitude of the standing outward current and its variance in WT, Gpr $179^{n o b}$, and $R G S 7^{-1-}$ / $R G S 11^{-/-}$rod BCs. We compared them to Trpm1 $1^{-/-}$rod BCs, where the channel is absent. Both the standing outward current and current variance of Gpr $179^{\text {nob5 }}, \mathrm{RGST}^{-1-} / \mathrm{RGS}_{11^{-/-}}$, and Trpm $1^{-/-}$rod BCs were similar (Fig. $7 B, C$; one-way ANOVAs: $p>0.05$ ) and all were significantly lower than WT (one-way ANOVA: standing current: WT vs $G p r 179^{n o b 5}, p<0.001$; WT vs $\mathrm{RGST}^{-/-} / \mathrm{RGS11}^{-/-}, \mathrm{p}<0.001$; WT vs $\operatorname{Trpm} 1^{-/-}, p<0.001$ 
A
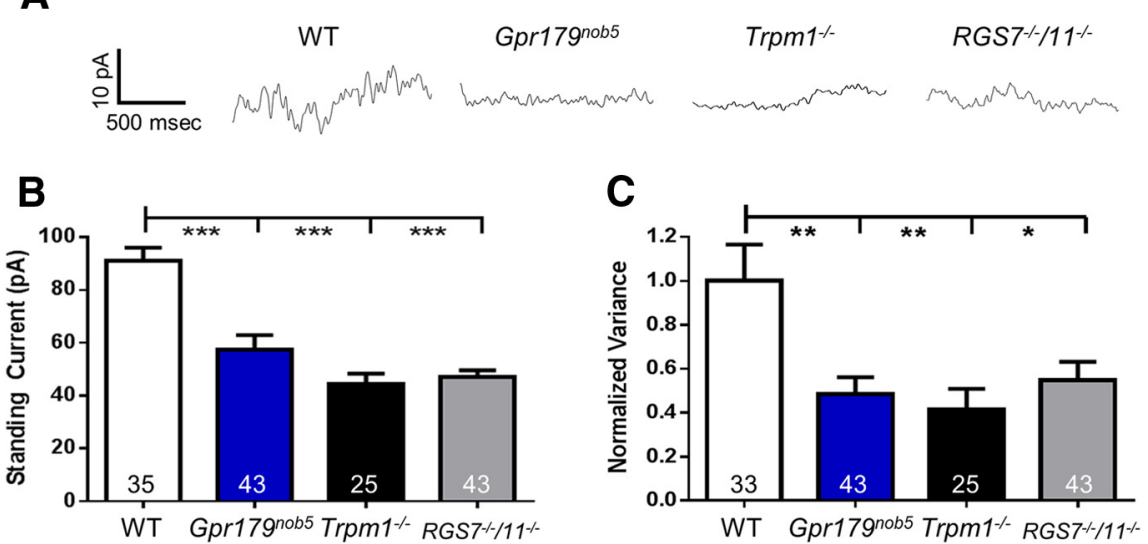

Figure 7. Gpr179 nob5, $\mathrm{TRPM}^{-1-}$, and $\mathrm{RGS}^{-1-} / \mathrm{RGS}^{-11^{-1-}}$ rod BCs have decreased standing currents and channel open

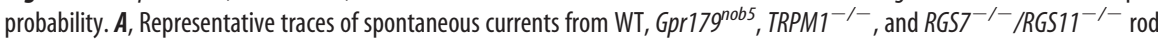
$B C$. Rod $B C s$ were held at $+50 \mathrm{mV}$ and $1.5 \mathrm{~s}$ sections of each recording were analyzed to yield the data in $\boldsymbol{B}$ and $\boldsymbol{C}$. Histograms compare average ( \pm SEM) $(\boldsymbol{B})$ standing current and $(\boldsymbol{C})$ current variance for WT, Gpr179 nob5 TRPM1 $^{-1-}$, and $R G S 7^{-1-}$, RGS $11^{-1-}$ rod BCs. Rod BCs from Gpr179nobs, TRPM1 $^{-1-}$, and $R G S 7^{-1-} / R G S 11^{-1-}$ have similar standing currents $(\boldsymbol{B})$ and current variance $(C)$ and all are significantly lower than WT (one-way ANOVA, ${ }^{*} p<0.05 ;{ }^{* *} p<0.01$, ${ }^{* * *} p<0.001$ ). Combined these data indicate that a channel that remains in $\mathrm{Gpr} 179^{\text {nob5 }}$ and $\mathrm{RGS}^{-/-} / \mathrm{RGS} 11^{-/-}$rod BCs has an open probability that is similar to rod BCs where the TRPM1 channel is absent $\left(\right.$ TRPM1 $\left.^{-/-}\right)$. The number of rod BCs in each experimental group is shown within each bar of the histograms.

variance: WT vs Gpr179 $9^{\text {nob }}, p<0.01$; WT vs $R G S 7^{-/-}$, $R G S 11^{-/-}, p<0.05$; WT vs $\left.\operatorname{Trpm}^{-/} p<0.01\right)$. These data indicate that even though the TRPM1 channel is expressed in

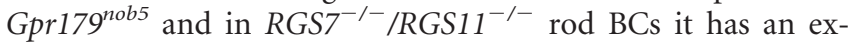
tremely low (near 0 ) open probability, similar to when the TRPM1 channel is absent. Our data suggest that GPR179 clusters RGS7 and RGS11 close to the TRPM1 channel and also interacts with TRPM1 to alter the ability of the channel to be gated directly by capsaicin.

\section{Discussion}

Visual function in starlight depends on the modulation of mGluR6, which gates the TRPM1 channel in rod BCs. In the current view, glutamate binding to mGluR6 (which happens in the dark) activates a trimeric G-protein complex (Nawy and von Gersdorff, 2011), which eventually leads to closure of the TRPM1 channel. Other critical elements of the mGluR6 G-protein cascade expressed on the tips of WT rod BCs are known because they reduce or eliminate this signaling pathway. They include nyctalopin, a leucine-rich repeat protein that is critical for the presence of TRPM1; GPR179, a seven transmembrane domain protein that is required for localization of a regulator of G-protein signaling (RGS) complex that contains RGS7, RGS11, G $\beta 3, G \beta 5$, and R9AP; and LRIT3, another leucine-rich repeat protein of unknown function (Gregg et al., 2003; Rao et al., 2007; Jeffrey et al., 2010; Cao et al., 2012; Dhingra et al., 2012; Shim et al., 2012; Zeitz et al., 2013). Our results show that mGluR6, nyctalopin, and TRPM1 continue to be localized to the OPL in the absence of GPR179 (Figs. 1, 2), but that the absence of GPR179 results in the mislocalization of the RGS7/RGS11 complex to the dendritic tips of DBCs containing the mGluR6/TRPM1 signaling complex (Orlandi et al., 2012). In contrast, in the absence of RGS7/ RGS11, GPR179 (Fig. 2), mGluR6, nyctalopin, and TRPM1 are expressed.

Careful analyses of the ERG b-wave responses in Gpr179 ${ }^{\text {nob5 }}$ mice showed a very small b-wave signal that was increased with longer flash duration. Consistent with this result, strong pharma- cological activation of mGluR6 in Gpr179 ${ }^{\text {nob5 }}$ rod BCs produced a response not evident in Trpm $1^{-/-}$rod BCs. Similar measurements from $R G S 7^{-/-} / R G S 11^{-/-}$ mice phenocopy both the ERG and rod $\mathrm{BC}$ responses to $\mathrm{CPPG}$ seen in the Gpr179 ${ }^{\text {nob5 }}$ rod BCs. Further, rod BCs from both Gpr179 nob5 and $R G S 7^{-1-}$ / $\mathrm{RGS}_{11^{-/-}}$mice had standing currents and variance that were similar to $\operatorname{Trpm} 1^{-1-}$ rod $\mathrm{BCs}$, indicating a remaining current of unknown identity, which has been noted previously (Morgans et al., 2009). Our current measures do not allow us to discriminate between the roles of GPR179 and the RGS complex in gating the TRPM1 channel opening through the mGluR6 cascade because the RGS complex is mislocalized in the absence of GPR179. However, the presence of GPR179 is required to maximize direct TRPM1 channel gating via capsaicin application, which does not involve the cascade. Capsaicin-mediated gating is altered in GPR179 ${ }^{\text {nob5 }}$ rod BCs, but is retained in $R G S 7^{-/-} / R_{G S 11^{-/-}}$rod BCs in which GPR179 is expressed normally (Fig. 6). We suggest this unique function of GPR179 is related to its direct protein:protein interaction with TRPM1. Together our results contribute new information to the ongoing construction of this G-protein cascade that is critical to night vision.

When glutamate binds mGluR6, its trimeric G-proteins are activated and GDP is exchanged for GTP on $\mathrm{G} \alpha_{0}$, producing activated $\mathrm{G} \alpha_{0}$-GTP and $\mathrm{G} \beta \gamma$, which become disassociated. Both components are membrane bound and likely in close proximity to TRPM1. This means that one or possibly both can interact with TRPM1 and are instrumental in channel closure, either directly or via another intermediate effector, yet to be identified. For the sake of simplicity, we shall discuss either $\mathrm{G} \alpha_{0}$-GTP or $\mathrm{G} \beta \gamma$ as the direct effector. Regardless of the identity of the active component, the interaction must be transient in nature. This view is supported by the fact that even when mGluR6 is maximally activated, either under dark-adapted conditions (Sampath and Rieke, 2004) or in the presence of L-AP4 (Fig. 7), there remains a standing current and nonzero channel open probability referred to as the dark current. Because the two studies were performed using very different protocols (e.g., dark vs APB and holding at $-60 \mathrm{mV}$ vs $+50 \mathrm{mV}$ ), we did not compare the currents.

Manipulations that reduce the level of the activated $\mathrm{G} \alpha_{0}$ all decrease either the light response or response to mGluR6 antagonists. These include adding GTP- $\gamma-\mathrm{S}$ to the patch pipette, deleting the RGS7/11 complex, or adding activated forms of $\mathrm{G} \alpha_{0}$ (Sampath and Rieke, 2004; Zhang et al., 2010; Cao et al., 2012; Shen et al., 2012; Shim et al., 2012). However, these manipulations cannot distinguish between the $\mathrm{G} \alpha_{0}$-GTP and $\mathrm{G} \beta \gamma$ models because decreasing $\mathrm{G} \alpha_{0}$-GDP concentrations necessarily increases free G $\beta \gamma$. Nawy and von Gersdorff (2011) found introduction of active $\mathrm{G} \beta \gamma$ but not $\mathrm{G} \alpha_{0}$ blocked the light response, and suggested G $\beta \gamma$ as the active component in TRPM1 channel closure (Shen et al., 2012). Our studies now show that the RGS complex is not required for cascade function, because in their absence a b-wave remains and the TRPM1 channel can be gated by strong mGluR6 cascade stimulation. Further, our studies show 
that in the absence of localized RGS proteins the standing current and channel open probability decrease to background levels, in contrast to what is seen when the cascade is maximally activated (Fig. 7). We propose this occurs in GRP179 $19^{n o b 5}$ and $R G S 7^{-1-}$, $R G S 11^{-1-}$ rod BCs because of increased concentrations of both $\mathrm{G} \alpha_{0}$-GTP and free $\mathrm{G} \beta \gamma$, which arise because of the loss of the RGS complex, resulting in complete TRPM1 closure.

In conclusion, we show that GPR179 interacts with TRPM1 and one of its functions is to localize RGS7 and RGS11 near the signaling complex (Orlandi et al., 2012). A second critical function of GPR179 is to set the state of the TRPM1 channel, allowing it to respond optimally to deactivation of the mGluR6 cascade. Understanding the various states of TRPM1, which we show are dependent on at least GPR179, at the molecular level may provide important clues as to how TRPM1 is gated by the mGluR6 cascade.

\section{References}

Audo I, Kohl S, Leroy BP, Munier FL, Guillonneau X, Mohand-Saïd S, Bujakowska K, Nandrot EF, Lorenz B, Preising M, Kellner U, Renner AB, Bernd A, Antonio A, Moskova-Doumanova V, Lancelot ME, Poloschek CM, Drumare I, Defoort-Dhellemmes S, Wissinger B, et al. (2009) TRPM1 is mutated in patients with autosomal-recessive complete congenital stationary night blindness. Am J Hum Genet 85:720-729. CrossRef Medline

Audo I, Bujakowska K, Orhan E, Poloschek CM, Defoort-Dhellemmes S, Drumare I, Kohl S, Luu TD, Lecompte O, Zrenner E, Lancelot ME, Antonio A, Germain A, Michiels C, Audier C, Letexier M, Saraiva JP, Leroy BP, Munier FL, Mohand-Saïd S, et al. (2012) Whole-exome sequencing identifies mutations in GPR179 leading to autosomal-recessive complete congenital stationary night blindness. Am J Hum Genet 90:321-330. CrossRef Medline

Boycott BB, Dowling JE, Kolb H (1969) Organization of the primate retina: light microscopy. Philos Trans R Soc Lond B Biol Sci 255:109-184. CrossRef

Cao Y, Masuho I, Okawa H, Xie K, Asami J, Kammermeier PJ, Maddox DM, Furukawa T, Inoue T, Sampath AP, Martemyanov KA (2009) Retinaspecific GTPase accelerator RGS11/G beta 5S/R9AP is a constitutive heterotrimer selectively targeted to mGluR6 in ON-bipolar neurons. J Neurosci 29:9301-9313. CrossRef Medline

Cao Y, Posokhova E, Martemyanov KA (2011) TRPM1 forms complexes with nyctalopin in vivo and accumulates in postsynaptic compartment of ON-bipolar neurons in mGluR6-dependent manner. J Neurosci 31: 11521-11526. CrossRef Medline

Cao Y, Pahlberg J, Sarria I, Kamasawa N, Sampath AP, Martemyanov KA (2012) Regulators of G protein signaling RGS7 and RGS11 determine the onset of the light response in ON bipolar neurons. Proc Natl Acad Sci U S A 109:7905-7910. CrossRef Medline

Dhingra A, Lyubarsky A, Jiang M, Pugh EN Jr, Birnbaumer L, Sterling P, Vardi N (2000) The light response of ON bipolar neurons requires G[alpha]o. J Neurosci 20:9053-9058. Medline

Dhingra A, Jiang M, Wang TL, Lyubarsky A, Savchenko A, Bar-Yehuda T, Sterling P, Birnbaumer L, Vardi N (2002) Light response of retinal ON bipolar cells requires a specific splice variant of Galpha(o). J Neurosci 22:4878-4884. Medline

Dhingra A, Ramakrishnan H, Neinstein A, Fina ME, Xu Y, Li J, Chung DC, Lyubarsky A, Vardi N (2012) G $\beta 3$ is required for normal light ON responses and synaptic maintenance. J Neurosci 32:11343-11355. CrossRef Medline

Ghosh KK, Bujan S, Haverkamp S, Feigenspan A, Wässle H (2004) Types of bipolar cells in the mouse retina. J Comp Neurol 469:70-82. CrossRef Medline

Gregg RG, Mukhopadhyay S, Candille SI, Ball SL, Pardue MT, McCall MA, Peachey NS (2003) Identification of the gene and the mutation responsible for the mouse nob phenotype. Invest Ophthalmol Vis Sci 44:378384. CrossRef Medline

Gregg RG, Kamermans M, Klooster J, Lukasiewicz PD, Peachey NS, Vessey KA, McCall MA (2007) Nyctalopin expression in retinal bipolar cells restores visual function in a mouse model of complete X-linked congen- ital stationary night blindness. J Neurophysiol 98:3023-3033. CrossRef Medline

Jeffrey BG, Morgans CW, Puthussery T, Wensel TG, Burke NS, Brown RL, Duvoisin RM (2010) R9AP stabilizes RGS11-G beta5 and accelerates the early light response of ON-bipolar cells. Vis Neurosci 27:9-17. CrossRef Medline

Kaneko A, Saito T (1983) Ionic mechanisms underlying the responses of off-center bipolar cells in the carp retina. II. Studies on responses evoked by transretinal current stimulation. J Gen Physiol 81:603-612. CrossRef Medline

Koike C, Obara T, Uriu Y, Numata T, Sanuki R, Miyata K, Koyasu T, Ueno S, Funabiki K, Tani A, Ueda H, Kondo M, Mori Y, Tachibana M, Furukawa T (2010) TRPM1 is a component of the retinal ON bipolar cell transduction channel in the mGluR6 cascade. Proc Natl Acad Sci U S A 107: 332-337. CrossRef Medline

Li Z, Sergouniotis PI, Michaelides M, Mackay DS, Wright GA, Devery S, Moore AT, Holder GE, Robson AG, Webster AR (2009) Recessive mutations of the gene TRPM1 abrogate ON bipolar cell function and cause complete congenital stationary night blindness in humans. Am J Hum Genet 85:711-719. CrossRef Medline

Masu M, Iwakabe H, Tagawa Y, Miyoshi T, Yamashita M, Fukuda Y, Sasaki H, Hiroi K, Nakamura Y, Shigemoto R (1995) Specific deficit of the ON response in visual transmission by targeted disruption of the mGluR6 gene. Cell 80:757-765. CrossRef Medline

McCall MA, Gregg RG (2008) Comparisons of structural and functional abnormalities in mouse b-wave mutants. J Physiol 586:4385-4392. CrossRef Medline

Miyake Y, Yagasaki K, Horiguchi M, Kawase Y, Kanda T (1986) Congenital stationary night blindness with negative electroretinogram. A new classification. Arch Ophthalmol 104:1013-1020. CrossRef Medline

Morgans CW, Weiwei L, Wensel TG, Brown RL, Perez-Leon JA, Bearnot B, Duvoisin RM (2007) Gbeta5-RGS complexes co-localize with mGluR6 in retinal ON-bipolar cells. Eur J Neurosci 26:2899-2905. CrossRef Medline

Morgans CW, Zhang J, Jeffrey BG, Nelson SM, Burke NS, Duvoisin RM, Brown RL (2009) TRPM1 is required for the depolarizing light response in retinal ON-bipolar cells. Proc Natl Acad Sci U S A 106:19174-19178. CrossRef Medline

Morgans CW, Brown RL, Duvoisin RM (2010) TRPM1: the endpoint of the mGluR6 signal transduction cascade in retinal ON-bipolar cells. Bioessays 32:609-614. CrossRef Medline

Nawy S (2004) Desensitization of the mGluR6 transduction current in tiger salamander On bipolar cells. J Physiol 558:137-146. CrossRef Medline

Nawy S, von Gersdorff H (2011) Bipolar cells in the vertebrate retina: from form to function. Introduction. Vis Neurosci 28:1-2. CrossRef Medline

Orlandi C, Posokhova E, Masuho I, Ray TA, Hasan N, Gregg RG, Martemyanov KA (2012) GPR158/179 regulate G protein signaling by controlling localization and activity of the RGS7 complexes. J Cell Biol 197:711-719. CrossRef Medline

Pardue MT, McCall MA, LaVail MM, Gregg RG, Peachey NS (1998) A naturally occurring mouse model of X-linked congenital stationary night blindness. Invest Ophthalmol Vis Sci 39:2443-2449. Medline

Peachey NS, Pearring JN, Bojang P Jr, Hirschtritt ME, Sturgill-Short G, Ray TA, Furukawa T, Koike C, Goldberg AF, Shen Y, McCall MA, Nawy S, Nishina PM, Gregg RG (2012a) Depolarizing bipolar cell dysfunction due to a Trpm1 point mutation. J Neurophysiol 108:2442-2451. CrossRef Medline

Peachey NS, Ray TA, Florijn R, Rowe LB, Sjoerdsma T, ContrerasAlcantara S, Baba K, Tosini G, Pozdeyev N, Iuvone PM, Bojang P Jr, Pearring JN, Simonsz HJ, van Genderen M, Birch DG, Traboulsi EI, Dorfman A, Lopez I, Ren H, Goldberg AF, et al. (2012b) GPR179 is required for depolarizing bipolar cell function and is mutated in autosomal-recessive complete congenital stationary night blindness. Am J Hum Genet 90:331-339. CrossRef Medline

Pearring JN, Bojang P Jr, Shen Y, Koike C, Furukawa T, Nawy S, Gregg RG (2011) A role for nyctalopin, a small leucine-rich repeat protein, in localizing the TRP melastatin 1 channel to retinal depolarizing bipolar cell dendrites. J Neurosci 31:10060-10066. CrossRef Medline

Rao A, Dallman R, Henderson S, Chen CK (2007) Gbeta5 is required for normal light responses and morphology of retinal ON-bipolar cells. J Neurosci 27:14199-14204. CrossRef Medline

Rood IM, Deegens JK, Merchant ML, Tamboer WP, Wilkey DW, Wetzels JF, 
Klein JB (2010) Comparison of three methods for isolation of urinary microvesicles to identify biomarkers of nephrotic syndrome. Kidney Int 78:810-816. CrossRef Medline

Saito T, Kaneko A (1983) Ionic mechanisms underlying the responses of off-center bipolar cells in the carp retina. I. Studies on responses evoked by light. J Gen Physiol 81:589-601. CrossRef Medline

Sampath AP, Rieke F (2004) Selective transmission of single photon responses by saturation at the rod-to-rod bipolar synapse. Neuron 41:431443. CrossRef Medline

Shen Y, Heimel JA, Kamermans M, Peachey NS, Gregg RG, Nawy S (2009) A transient receptor potential-like channel mediates synaptic transmission in rod bipolar cells. J Neurosci 29:6088-6093. CrossRef Medline

Shen Y, Rampino MA, Carroll RC, Nawy S (2012) G-protein-mediated inhibition of the Trp channel TRPM1 requires the G $\beta \gamma$ dimer. Proc Natl Acad Sci U S A 109:8752-8757. CrossRef Medline

Shim H, Wang CT, Chen YL, Chau VQ, Fu KG, Yang J, McQuiston AR, Fisher
RA, Chen CK (2012) Defective retinal depolarizing bipolar cells in regulators of G protein signaling (RGS) 7 and 11 double null mice. J Biol Chem 287:14873-14879. CrossRef Medline

Slaughter MM, Miller RF (1983) An excitatory amino acid antagonist blocks cone input to sign-conserving second-order retinal neurons. Science 219: 1230-1232. CrossRef Medline

Zeitz C, Jacobson SG, Hamel CP, Bujakowska K, Neuillé M, Orhan E, Zanlonghi X, Lancelot ME, Michiels C, Schwartz SB, Bocquet B, Antonio A, Audier C, Letexier M, Saraiva JP, Luu TD, Sennlaub F, Nguyen H, Poch O, Dollfus H, et al. (2013) Whole-exome sequencing identifies LRIT3 mutations as a cause of autosomal-recessive complete congenital stationary night blindness. Am J Hum Genet 92:67-75. CrossRef Medline

Zhang J, Jeffrey BG, Morgans CW, Burke NS, Haley TL, Duvoisin RM, Brown RL (2010) RGS7 and -11 complexes accelerate the ONbipolar cell light response. Invest Ophthalmol Vis Sci 51:1121-1129. CrossRef Medline 